OPEN ACCESS

Edited by:

Magdalena Radulescu,

University of Pitesti, Romania

Reviewed by:

Alexandra Horobet,

Bucharest Academy of Economic

Studies, Romania

Shubham Mahajan,

Shri Mata Vaishno Devi University,

India

*Correspondence:

Qingzhen Yao

yao0213@126.com

Specialty section:

This article was submitted to

Environmental Economics and

Management,

a section of the journal

Frontiers in Environmental Science

Received: 04 January 2022

Accepted: 17 January 2022

Published: 14 February 2022

Citation:

Yao Q and Shao L (2022) Research on

Emission Reduction Strategies of Building Materials Manufacturers and Real Estate Developers in the Context

of Carbon Trading.

Front. Environ. Sci. 10:848260.

doi: $10.3389 /$ fenvs.2022.848260

\section{Research on Emission Reduction Strategies of Building Materials Manufacturers and Real Estate Developers in the Context of Carbon Trading}

\author{
Qingzhen Yao* and Liangshan Shao \\ Systems Engineering Institute, Liaoning Technical University, Huludao, China
}

External carbon trading, free transfer between enterprises and, internal carbon trading are the primary forms of carbon trading between real estate enterprises and building materials enterprises. This paper establishes the Stackelberg game model under three conditions of carbon trading and analyzes the emission reduction strategies of real estate developers and building materials manufacturers. The results show that the low carbon degree of building materials is proportional to that of residential buildings and is affected by the external carbon trading price; The order quantity of building materials is directly proportional to the low carbon degree of building materials and housing and has nothing to do with the form of carbon trading; When only external carbon trading is carried out, the maximum profit of real estate developers is positively correlated with carbon quota and external carbon trading price, and the maximum profit of building materials manufacturers is positively correlated with carbon quota and negatively correlated with external carbon trading price. When internal carbon trading and external carbon trading coexist, the maximum profit of real estate developers increases with the rise of carbon quota, and the maximum profit of building materials manufacturers does not change significantly with the rise of carbon quota; Internal carbon trading can increase the profits of building materials manufacturers and reduce the selling prices of building materials, thereby increasing their enthusiasm for carbon emission reduction. An example is given to verify the effectiveness of the above conclusions.

Keywords: carbon trading, low carbon housing, carbon emission reduction, Stackelberg game, real estate enterprises, building materials enterprises

\section{INTRODUCTION}

According to the "China Statistical Yearbook," the average annual growth rate of urban residential electricity consumption from 2009 to 2018 reached $11.9 \%$, and it still maintained a rapid growth trend (National Bureau of Statistics of China, 2020). Therefore, low-carbon housing must be used to reduce carbon emissions. Low-carbon housing minimizes carbon dioxide emissions during the life cycle of building materials production, construction, and operation and maintenance stages (Shen and Li, 2011). It can provide residents with residential buildings with reasonable comfort. Low-carbon housing is realized by low-carbon building materials and low-carbon construction technology. Therefore, the 
efforts of building materials and real estate developers are crucial to the development of low-carbon housing. With technology development, more and more low-carbon products are used in residential buildings, such as LOW-E glass, aluminum alloy materials, recycled concrete, etc. These low-carbon materials play a significant role in reducing emissions in residential buildings. To reduce carbon emissions, China has launched a national carbon trading market on July 16, 2021. In carbon trading, the choice of carbon trading strategies for building materials and real estate developers has become an important research issue.

Carbon emissions in the whole life cycle of buildings refer to carbon dioxide emissions in the stages of mining, production, and transportation of building materials, construction, maintenance, and demolition (Chang et al., 2010; Lin and Liu, 2015; Ma and Cai, 2018). In the past 2 decades, carbon emissions from building materials have been the primary source of carbon emissions in China, among which steel, commercial concrete, wall building materials, mortar, and other building materials are the primary sources of carbon emissions from buildings (Luo et al., 2019; Zhu et al., 2020). Therefore, it is of great significance to study the carbon emissions of building materials. The carbon emission of residential buildings is related to the area and the structure of the building. Buildings with different structures have different carbon emissions. The carbon emissions of urban residential buildings are significantly higher than those of rural residential buildings. The carbon emissions of concrete-structured residential buildings are higher than wooden-structured residential buildings $(\mathrm{Qu}$ et al., 2014; Xiao et al., 2016; Xu et al., 2020).

In recent years, the issue of carbon emissions of manufacturing companies has become a research hotspot, and many researchers have also been concerned about carbon trading in the supply chain. Carbon trading can effectively promote carbon emission reduction in enterprises (Chen and $\mathrm{Hu}, 2018$ ). Benjaafar et al. (2013) and Xu et al. (2016) studied the supply chain carbon emission reduction model and found that the amount of carbon allowances is positively correlated with carbon emissions, and the carbon price is negatively correlated with the total cost of abatement. Many scholars have drawn the following conclusions through the supply chain decision-making model in the context of carbon trading: Carbon trading can effectively reduce the carbon emissions of products, but it also reduces the sales of production (Yang, 2020); Excessive carbon emission reduction is not conducive to the sustainable development of enterprises (Zhang et al., 2020); The most effective way to improve both economic and environmental benefits at the same time is to encourage the introduction of carbon reduction technologies and guide consumers to increase their ecological preferences (Ma et al., 2021;Wang and Hou, 2020; Zhu et al., 2019); whether the supply chain adopts low-carbon technologies is affected by factors such as carbon price volatility, carbon tax rates, and carbon reduction costs (Song et al., 2018; Ding et al., 2020).

Game Theory is an Effective Tool for Studying Carbon Emissions of Different Stakeholders (Chen and Hu, 2018). Wang and Cheng, (2021) used evolutionary game theory to analyze the optimal carbon emission strategies of manufacturers and suppliers in the context of carbon trading and found that carbon trading prices play an essential role in the stability of the system; Shen et al. (2016) took small and medium-sized enterprises as the research object and constructed a Stackelberg game model to explore their optimal emission reduction, order volume and product pricing under the influence of carbon trading; Bai et al. (2017) analyzed the impact of carbon trading mechanism on corporate low-carbon technology innovation sharing strategies and benefits through a dynamic game model; Wang et al. (2016) examined the conflicts of interest of companies in the supply chain in the process of cooperative emission reduction, and discussed the ways of cost-sharing and benefit-sharing to achieve coordinated emission reduction in the supply chain.

Existing research results mainly focus on evaluating lowcarbon technologies for buildings and optimizing carbon emission reduction strategies under mandatory environmental control policies. There is little research on emission reduction methods, such as carbon quota trading through the market. In addition, the analysis of carbon trading in the construction field is still in its initial stage. The sporadic results are more from macromanagement and rarely from the perspective of carbon emission reduction stakeholders to study their micro behavior willingness and decision-making.

Carbon dioxide emissions are enormous in the whole life cycle of residential buildings, and low-carbon residential buildings can reduce carbon dioxide emissions. The realization of low-carbon housing requires the joint efforts of building materials manufacturers and real estate developers. However, enterprises aim to maximize profits, so enterprises need the active guidance of government policies in lowcarbon development. Carbon trading is an effective policy tool to promote enterprises to reduce carbon emissions and guide the lowcarbon innovation of enterprises. This paper used the Stackelberg game theory to address the following problems:

1. Is there an optimal carbon emission reduction strategy in different carbon trading forms for building materials manufacturers and real estate developers?

2. If there are optimal carbon emission reduction strategies, how to calculate these strategies?

3. What is the internal connection between the optimal price of building materials, the optimal usage of building materials, the optimal low-carbon degree of building materials, and the optimal low-carbon degree of residential buildings?

\section{DESCRIPTION}

This article considers that the building materials needed by real estate developers are directly supplied by building materials vendors. The government's carbon quotas restrict the carbon emissions of both parties. In the case of carbon quota constraints, real estate developers and building materials merchants will have insufficient carbon quotas on both sides, surpluses on both sides, and insufficient surplus on one side. When one party has inadequate carbon allowances and another has surplus carbon allowances, building materials companies or real estate developers can choose internal carbon trading or external carbon trading. The best strategy for real estate developers and 
TABLE 1 | Details of main variables.

\begin{tabular}{|c|c|c|c|}
\hline Meaning & Symbol & Meaning & Symbol \\
\hline Selling price per unit area & $P_{k}$ & Initial carbon emissions per unit of building materials "i” & $E_{j}$ \\
\hline Total usage of building materials "i" & $q$ & External carbon trading price & $T_{1}$ \\
\hline Unit selling price of building materials $i$ & $m$ & Internal carbon trading price & $T_{2}$ \\
\hline Other costs per unit area of residence except building materials " $i$ " & $s$ & Shipping cost per unit of building materials & $f$ \\
\hline Investment in emission reduction by real estate developers & $\beta_{k}$ & Production cost per unit of building materials & $J_{c}$ \\
\hline Emission reduction investment of building materials manufacturers & $\beta_{j}$ & Use coefficient of building material " $i$ " per unit of residential area & $1 / \alpha$ \\
\hline Low carbon degree of housing & $y$ & Total profit of building materials business & $L_{j}$ \\
\hline Low carbon degree of building materials "i" & $x$ & Real estate developer's total profit & $L_{k}$ \\
\hline Carbon allowances for real estate developers & $C_{k}$ & Price of residence & $P_{k}$ \\
\hline Initial carbon emissions per unit area of residence & $E_{k}$ & Residential sales & $\alpha q$ \\
\hline Carbon quota for building materials business & $C_{j}$ & Unit cost of building materials "i" & $J_{C}$ \\
\hline
\end{tabular}

building materials companies depends on profit, and the maximum profit determines the best strategy. In the context of carbon trading, building materials manufacturers' and real estate developers' profits are affected by building materials prices, sales volume, cost, low-carbon degree of products, carbon quotas, and corporate emission reduction investments. Therefore, the variables are shown in Table 1.

In the context of carbon trading, there are internal and external carbon trading models, and the sales of products are also in line with market laws. To simplify the model, we made the following assumptions by drawing lessons from the research results of other scholars:

\section{- Assumption 1}

Real estate developers and building materials companies can increase the low-carbon level of their products by increasing investment $(0<x<1,0<y<1)$, and with the increase of lowcarbon degree, the carbon emission reduction produced by the unit investment of capital decreases. Enterprise's emission reduction investment and low carbon degree meet $C(x)=$ $\frac{1}{2} B x^{2}$ (Wei-Jun, 2010).

\section{- Assumption 2}

It is assumed that when considering internal and external carbon trading after the real estate developers invest in emission reduction, the carbon quota can meet their own needs and has a surplus. In contrast, the carbon quota of building materials manufacturers is insufficient.

\section{- Assumption 3}

The price of external carbon trading is determined by the carbon market, and the price of internal carbon trading is determined by building materials dealers and real estate developers. The price of external carbon trading is greater than the price of internal carbon trading $\left(T_{1}>T_{2}\right)$.

\section{- Assumption 4}

The sales volume of housing produced by real estate developers satisfies $\alpha q=a-b P_{k}(a, b$ are constants).

\section{CARBON TRADING MODEL}

This paper uses Stackelberg game theory to establish a two-level supply chain decision model led by real estate developers and followed by building materials dealers and uses reverse induction to find the optimal answer to explore the impact of various decision variables on corporate decisions.

The Stackelberg game was first proposed by Von Stackelberg. It is a dynamic game with complete information. The game process is as follows:

1) Enterprise 1 chooses production output $q_{1} \geq 0$;

2) Enterprise 2 observes $q_{1}$, and then selects production output $q_{2}$

3) The profit function of firm $i \quad(=1,2)$ is $\pi_{i}=\left(q_{i}, q_{j}\right)=P(Q) q_{i}-C_{i}\left(q_{i}\right), i, j=1,2$

Here, $Q=q_{1}+q_{2}$ is the total supply of products, $P(Q)$ is the price function, and $C_{i}\left(q_{i}\right)$ is the cost function of firm $i(=1,2)$.

\subsection{External Carbon Trading Model}

Real estate developers invest in emission reduction, carbon allowances can meet their own needs and have a surplus, and the remaining part is externally traded through the carbon market. The profit function of real estate developers is shown in Eq. 1:

$$
\begin{gathered}
L_{k}^{(1)}=C_{k} T_{1}-T_{1}(1-y) \alpha q E_{k}+\alpha q P_{k}-m q-s \alpha q-\frac{1}{2} \beta_{k} y^{2} \\
\text { s.t. }(1-y) \alpha q E_{k}<C_{k}
\end{gathered}
$$

After building materials companies invest in carbon emission reduction, carbon allowances still cannot meet their own needs and must be purchased from the external carbon market. The profit function of building materials companies is shown in Eq. 2:

$$
\begin{gathered}
L_{j}^{(1)}=C_{j} T_{1}-T_{1}(1-x) q E_{j}+q m-J_{c} q-\frac{1}{2} \beta_{j} x^{2} \\
\text { s.t. }(1-x) q E_{j}>C_{j}
\end{gathered}
$$

According to the optimization theory, the Lagrange multiplier needs to be established to solve the optimal value of the above model, as shown in Eq. 3: 


$$
\begin{gathered}
L(x, \lambda)=-B^{T} X+\lambda\left(X^{T} A X-C\right) \\
\qquad \begin{array}{l}
\frac{\partial L}{\partial x}=0 \\
g(x) \leq 0 \\
\lambda \geq 0 \\
\lambda g(x)=0
\end{array}
\end{gathered}
$$

Proposition 1 : When real estate developers have surplus carbon quotas and building materials companies have insufficient carbon quotas, and when only external carbon trading is conducted, there are $q_{o p t}$, mopt, xopt, and $y_{o p t}$, which maximize the profits of real estate developers and building materials companies.

Proof. According to Hypothesis 4, we can get $P_{k}=\frac{a-\alpha q}{b}$. According to the inverse solution principle of the Stackelberg game, first, assume that building materials' sales price $(m)$ has been given. The real estate developer can maximize the profit by deciding the order quantity $(q)$ under the constraints. The model is described as follows:

$$
\begin{gathered}
\max L_{k}^{(1)}=C_{k} T_{1}-T_{1}(1-y) \alpha q E_{k}+\alpha q \frac{a-\alpha q}{b}-m q-s \alpha q-\frac{1}{2} \beta_{k} y^{2} \\
\text { s.t. }(1-y) \alpha q E_{k}<C_{k} \\
L_{k}(q, \lambda 1)^{(1)}=-\left(C_{k} T_{1}-T_{1}(1-y) \alpha q E_{k}+\alpha q P_{k}-m q-s \alpha q\right. \\
\left.-\frac{1}{2} \beta_{k} y^{2}\right)+\lambda 1\left[(1-y) \alpha q E_{k}-C_{k}\right]
\end{gathered}
$$

Here, $\lambda_{1}$ is the Lagrange multiplier $\left(\lambda_{1} \geq 0\right)$. According to Eq. 3, the solution to the above problem should satisfy Eq. 6.

$$
\left\{\begin{array}{l}
\frac{\partial L(q, \lambda 1)}{\partial q}=0 \\
(1-y) q E_{j}<C_{j} \\
\lambda_{1} \geq 0 \\
\lambda_{1}\left[(1-y) \alpha q E_{k}-C_{k}\right]=0
\end{array}\right.
$$

According to Eq. 6, we can get:

$$
q^{(1)}=\frac{-b m+\alpha\left(E_{k} T_{1} b y-E_{k} T_{1} b+a-b s\right)}{2 \alpha^{2}}
$$

Bring Eq. 7 into Eq. 2., we get the optimal strategy model of building material price $\left(m_{o p t}\right)$, which is described as follows:

$$
\begin{gathered}
\max L_{j}^{(1)}=C_{j} T_{1}-T_{1}(1-x)\left(\frac{-b m+\alpha\left(E_{k} T_{1} b y-E_{k} T_{1} b+a-b s\right)}{2 \alpha^{2}}\right) E_{j} \\
+q m-J_{c}\left(\frac{-b m+\alpha\left(E_{k} T_{1} b y-E_{k} T_{1} b+a-b s\right)}{2 \alpha^{2}}\right)-\frac{1}{2} \beta_{j} x^{2} \\
\text { s.t. }(1-x) q E_{j}>C_{j}
\end{gathered}
$$

Similarly, it is solved by introducing Lagrange multiplier, we can get Eq. 9:

$$
\begin{aligned}
& L\left(m, \lambda_{2}\right)^{(1)}=-L_{j}+\lambda_{4} \\
& {\left[C_{j}-(1-x) \frac{a \alpha-m b-s b \alpha-(1-y) \alpha b E_{k} T_{1}}{2 \alpha^{2}} E_{j}\right]}
\end{aligned}
$$

Here, $\lambda_{2}$ is the Lagrangian multiplier $\left(\lambda_{2} \geq 0\right)$. According to Eq. 3, the solution to the above problem should satisfy Eq. 10.

$$
\left\{\begin{array}{l}
\frac{\partial L\left(m, \lambda_{2}\right)}{\partial m}=0 \\
(1-x) q E_{j}>C_{j} \\
\lambda_{2} \geq 0 \\
\lambda_{2}\left[(1-x) \alpha q E_{k}-C_{k}\right]=0
\end{array}\right.
$$

According to Eq. 10, we can get:

$$
\begin{gathered}
\lambda_{2}=0 \\
m_{\text {opt }}^{(1)}=\frac{a \alpha+b\left(-E_{j} T_{1} x+E_{j} T_{1}+E_{k} T_{1} \alpha y-E_{k} T_{1} \alpha+J_{c}-\alpha s\right)}{2 b}
\end{gathered}
$$

Taking Eq. 11 into Eq. 7, we can get Eq. 12:

$$
q_{\text {opt }}^{(1)}=\frac{a \alpha+\alpha\left(b E_{k} T_{1} y-E_{k} T_{1} b-b s\right)+b\left(E_{j} T_{1} x-E_{j} T_{1}-J_{c}\right)}{4 \alpha^{2}}
$$

Bring Eqs 11 and 12 into Eqs. 1 and 2 respectively to obtain Eqs 13 and 14:

$$
\begin{aligned}
& \frac{\partial^{2} L_{k}^{(1)}}{\partial^{2} y}=\frac{E_{k}^{2} T_{1}^{2} b}{8}-\beta_{k} \\
& \frac{\partial^{2} L_{j}^{(1)}}{\partial^{2} x}=\frac{b E_{j}^{2} T_{1}^{2}}{4 \alpha^{2}}-\beta_{j}
\end{aligned}
$$

Considering that the developer's investment in emission reduction is relatively large, so $\frac{\partial^{2} L_{k}^{(1)}}{\partial^{2} y}<0, \frac{\partial^{2} L_{j}^{(1)}}{\partial^{2} x}<0$ and $L_{k}(\mathrm{y})$ and $L_{j}(x)$ are convex functions. Let $\frac{\partial L_{k}}{\partial y}=0, \frac{\partial L_{j}}{\partial x}=0$, Let $a=0$, $b=0$, we can get Eqs 15 and 16 .

$$
\begin{aligned}
& x_{o p t}^{(1)}=\frac{2 B_{k} E_{j} T_{1}\left(E_{j} T_{1} b+E_{k} T_{1} b \alpha+J_{c} b-a \alpha+b \alpha s\right)}{-8 B_{j} B_{k} \alpha^{2}+B_{j} E_{k}^{2} T_{1}^{2} b \alpha^{2}+2 B_{k} E_{j}^{2} T_{1}^{2} b} \\
& y_{o p t}^{(1)}=\frac{\alpha B_{j} E_{k} T_{1}\left(E_{j} T_{1} b+E_{k} T_{1} b \alpha+J_{c} b-a \alpha+b \alpha s\right)}{-8 B_{j} B_{k} \alpha^{2}+B_{j} E_{k}^{2} T_{1}^{2} b \alpha^{2}+2 B_{k} E_{j}^{2} T_{1}^{2} b}
\end{aligned}
$$

\subsection{Internal Carbon Trading Model 3.2.1 The Remaining Carbon Quotas of Real Estate Developers Are Free for Use by Building Materials Companies}

Some building materials manufacturers are subsidiaries of real estate developers, or building materials manufacturers and real estate developers belong to the same parent company. In this case, one of the building materials manufacturers and real estate 
developers have a surplus carbon quota and will be used by the other party free of charge. It can be considered in two cases: 1 . The carbon quota of real estate developers is surplus and sufficient for building materials manufacturers; 2 . The remaining carbon quota of the real estate developers is excess and insufficient to meet the needs of the building materials manufacturers, and the building materials manufacturers need to purchase.

- Situation 1:

$$
\begin{gathered}
L_{k}^{(2)}=T_{1}\left(C_{k}-(1-y) \alpha q E_{k}-\left((1-x) q E_{j}-C_{j}\right)\right)+\alpha q P_{k}-m q \\
-s \alpha q-\frac{1}{2} \beta_{k} y^{2} \\
\text { s.t. }(1-y) \alpha q E_{k}<C_{k} \\
L_{j}^{(2)}=q m-J_{c} q-\frac{1}{2} \beta_{j} x^{2} \\
\text { s.t. }\left\{\begin{array}{l}
(1-x) q E_{j}>C_{j} \\
C_{k}+C_{j}>(1-y) \alpha q E_{k}+(1-x) q E_{j}
\end{array}\right.
\end{gathered}
$$

Proposition 2.: When the carbon quota of real estate developers is surplus, the carbon quota of building materials manufacturers is insufficient, and the remaining carbon quota of real estate developers is free and sufficient for building materials manufacturers. There are $q_{o p t}$, mopt, xopt, and $y_{o p t}$, which maximizes the profits of real estate developers and building materials manufacturers.

Proof. It is the same as the solution method of the external carbon trading model, assuming that the selling price of building materials has been determined, and the Lagrangian multipliers are constructed to obtain:

$$
\begin{aligned}
L_{k}\left(q, \lambda_{3}, \lambda_{4}\right)^{(2)}= & -\left(T_{1}\left(C_{k}-(1-y) \alpha q E_{k}-\left((1-x) q E_{j}-C_{j}\right)\right)\right. \\
& \left.+\alpha q P_{k}-m q-s \alpha q-\frac{1}{2} \beta_{k} y^{2}\right) \\
& +\lambda_{3}\left[(1-y) \alpha q E_{k}-C_{k}\right] \\
& +\lambda_{4}\left[(1-y) \alpha q E_{k}+(1-x) q E_{j}-C_{k}-C_{j}\right]
\end{aligned}
$$

Here, $\lambda_{3}$ and $\lambda_{4}$ is the Lagrange multiplier $\left(\lambda_{3}, \lambda_{4} \geq 0\right)$. According to Eq. 3, the solution to the above problem should satisfy:

$$
\left\{\begin{array}{l}
\frac{\partial L\left(q, \lambda_{1}\right)^{(2)}}{\partial q}=0 \\
(1-y) \alpha q E_{k}<C_{k} \\
\lambda_{3} \geq 0, \lambda_{4} \geq 0 \\
\lambda_{3}\left[(1-y) \alpha q E_{k}-C_{k}\right]=0 \\
\lambda_{4}\left[(1-y) \alpha q E_{k}+(1-x) q E_{j}-C_{k}-C_{j}\right]=0
\end{array}\right.
$$

We can get:

$$
q=\frac{b\left(E_{j} T_{1} x-E_{j} T_{1}-m\right)+\alpha\left(E_{k} T_{1} b y-E_{k} T_{1} b+a-b s\right)}{2 \alpha^{2}}
$$

Bringing Eq. 19 into Eq. 18, we get Eq. 21:

$\max L_{j}^{(2)}=\frac{b\left(E_{j} T_{1} x-E_{j} T_{1}-m\right)+\alpha\left(E_{k} T_{1} b y-E_{k} T_{1} b+a-b s\right)}{2 \alpha^{2}}\left(m-J_{c}\right)-\frac{1}{2} \beta_{j} x^{2}$

Solving by introducing Lagrange multipliers, Eq. 22 is obtained:

$$
L_{j}\left(m, \lambda_{5}\right)^{(2)}=-\left(q m-J_{c} q-\frac{1}{2} \beta_{j} x^{2}\right)+\lambda_{5}\left[C_{k}-(1-y) \alpha q E_{k}\right]
$$

$$
\left\{\begin{array}{l}
\frac{\partial L_{j}\left(m, \lambda_{5}\right)^{(2)}}{\partial m}=0 \\
(1-x) q E_{j}>C_{j} \\
\lambda_{5} \geq 0 \\
\lambda_{5}\left[C_{k}-(1-y) \alpha q E_{k}\right]=0
\end{array}\right.
$$

We can get: $\lambda_{5}=0$

$$
m_{\text {opt }}^{(2)}=\frac{a \alpha+b\left(E_{j} T_{1} x-E_{j} T_{1}+E_{k} T_{1} \alpha y-E_{k} T_{1} \alpha+J \alpha-\alpha s\right)}{2 b}
$$

Bringing Eq. 23 into Eq. 20, we get:

$q_{o p t}^{(2)}=\frac{a \alpha+\alpha\left(b E_{k} T_{1} y-E_{k} T_{1}-b s\right)+b\left(E_{j} T_{1} x-E_{j} T_{1}-J_{c}\right)}{4 \alpha^{2}}$

Bring Eq. 23 and Eq. 24 into Eq. 17 and Eq. 18 respectively, and it is easy to prove that $\frac{\partial^{2} L_{k}^{(2)}}{\partial^{2} y}<0, \frac{\partial^{2} L_{j}^{(2)}}{\partial^{2} x}<0$.So $L_{k}(y)^{(2)}, L_{j}(x)^{(2)}$ is a convex function, $\frac{\partial L_{k}^{(2)}}{\partial y}=0, \frac{\partial L_{j}^{(2)}}{\partial x}=0$, we can get Eqs 25 and 26

- Situation 2:

$$
\begin{gathered}
L_{k}^{(3)}=\alpha q P_{k}-m q-s \alpha q-\frac{1}{2} \beta_{k} y^{2} \\
\text { s.t. }(1-y) \alpha q E_{k}<C_{k} \\
L_{j}^{(3)}=-T_{1}\left((1-x) q E_{j}-C_{j}-\left(C_{k}-(1-y) \alpha q E_{k}\right)\right)+q m-J_{c} q-\frac{1}{2} \beta_{j} x^{2} \\
\text { s.t. }(1-x) q E_{j}>C_{j}
\end{gathered}
$$

Proposition 3. The remaining carbon quotas of real estate developers are surplus, and they are not enough to meet the needs of building materials companies. At this time, building materials companies need to purchase carbon emission indicators from the external carbon market. In this case, there are qopt, mopt, xopt, and yopt, which maximize the profits of real estate developers and building materials companies.

Proof. Referring to the proof process of Proposition 1 and introducing Lagrange multipliers to solve Eq. 25, we get Eq. 27:

$$
L_{k}\left(q, \lambda_{6}\right)^{(3)}=-\left(\alpha q P_{k}-m q-s \alpha q-\frac{1}{2} \beta_{k} y^{2}\right)+\lambda_{6}\left[(1-y) \alpha q E_{k}-C_{k}\right]
$$




$$
\left\{\begin{array}{l}
\frac{\partial L_{k}\left(q, \lambda_{6}\right)^{(3)}}{\partial q}=0 \\
(1-y) \alpha q E_{k}<C_{k} \\
\lambda_{6} \geq 0 \\
\lambda_{6}\left[C_{k}-(1-y) \alpha q E_{k}\right]=0
\end{array}\right.
$$

We can get:

$$
q^{(3)}=\frac{-b m+\alpha(a-b s)}{2 \alpha^{2}}
$$

Bringing Eq. 28 into Eq. 26 and constructing Lagrange multipliers, we can get Eq. 29:

$$
m_{o p t}^{(3)}=\frac{a \alpha+b\left(-x E_{j} T_{1}+E_{j} T_{1}-E_{k} T_{1} \alpha y+E_{k} T_{1} \alpha+J_{c}-\alpha s\right)}{2 b}
$$

Bringing Eq. 29 into Eq. 28, we get Eq. 30:

$$
q_{o p t}^{(3)}=\frac{a \alpha+\alpha\left(b E_{k} T_{1} y-b E_{k} T_{1}-b s\right)+b\left(E_{j} T_{1} x-E_{j} T_{1}-J_{c}\right)}{4 \alpha^{2}}
$$

Bring Eq. 29 and Eq. 30 into Eq. 25 and Eq. 26 respectively, and it is easy to prove that $\frac{\partial^{2} L_{k}^{(3)}}{\partial^{2} y}<0, \frac{\partial^{2} L_{j}^{(3)}}{\partial^{2} x}<0$.So $L_{k}(y)^{(3)}, L_{j}(x)^{(3)}$ is a convex function, $\frac{\partial L_{k}^{(3)}}{\partial y}=0, \frac{\partial L_{j}^{(3)}}{\partial x}=0$, we can get Eq. 31, Eq. 32 .

$$
\begin{aligned}
& x_{o p t}^{(3)}=\frac{2 B_{k} E_{j} T_{1}\left(E_{j} T_{1} b+E_{k} T_{1} b \alpha+J_{c} b-a \alpha+b \alpha s\right)}{-8 B_{j} B_{k} \alpha^{2}+B_{j} E_{k}^{2} T_{1}^{2} b \alpha^{2}+2 B_{k} E_{j}^{2} T_{1}^{2} b} \\
& y_{\text {opt }}^{(3)}=\frac{\alpha B_{j} E_{k} T_{1}\left(E_{j} T_{1} b+E_{k} T_{1} b \alpha+J_{c} b-a \alpha+b \alpha s\right)}{-8 B_{j} B_{k} \alpha^{2}+B_{j} E_{k}^{2} T_{1}^{2} b \alpha^{2}+2 B_{k} E_{j}^{2} T_{1}^{2} b}
\end{aligned}
$$

\subsubsection{Carbon Trading Model When Internal and External Carbon Trading Coexist}

When real estate developers and building materials companies conduct internal and external carbon trading processes, the following two situations will occur 1 . Internal carbon trading cannot meet building manufacturers' needs, and carbon allowances need to be purchased from outside; 2 . Internal carbon trading can meet the needs of building materials companies, and real estate developers will sell the remaining carbon allowances on the external market.

- Situation 1:

$$
\begin{aligned}
L_{k}^{(4)}= & C_{k} T_{2}-T_{2}(1-y) \alpha q E_{k}+\alpha q P_{k}-m q-s \alpha q-\frac{1}{2} \beta_{k} y^{2} \\
& \text { s.t. } C_{k}-(1-y) \alpha q E_{k}>0 \\
L_{j}^{(4)}=- & T_{2}\left[C_{k}-(1-y) \alpha q E_{k}\right]-T_{1}\left[(1-x) q E_{j}-C_{j}-C_{k}\right. \\
& \left.+(1-y) \alpha q E_{k}\right]+q m-J_{c} q-\frac{1}{2} \beta_{j} x^{2} \\
& \text { s.t. }(1-x) q E_{j}-C_{j}-C_{k}+(1-y) \alpha q E_{k}>0
\end{aligned}
$$

Proposition 4 : Real estate developers sell the remaining carbon allowances to building materials dealers through internal transactions, which still cannot meet the needs of building materials dealers. At this time, building materials dealers still need to purchase carbon emission indicators from outside. In this case, there are optimal $q_{o p t}, m_{o p t,}$ and $x_{o p t}$ and $y_{o p t}$, maximizing the profits of real estate developers and building materials companies.

Proof. Constructing Lagrange multipliers for Eqs $\mathbf{3 3}$ and $\mathbf{3 4}$ and solving, we can get Eqs. 35 and 36.

$$
\begin{gathered}
m_{\text {opt }}^{(4)}=\frac{a \alpha+b\left(-E_{j} T_{1} x+E_{j} T_{1}-E_{k} T_{1} \alpha y+E_{k} T_{1} \alpha+2 E_{k} T 2 \alpha y-2 E_{k} T 2 \alpha+J_{c}-\alpha s\right)}{2 b} \\
q_{\text {opt }}^{(4)}=\frac{a \alpha+\alpha b\left(E_{k} T_{1} y-E_{k} T_{1}-s\right)+b\left(E_{j} T_{1} x-E_{j} T_{1}-J_{c}\right)}{4 \alpha^{2}}
\end{gathered}
$$

Bring Eqs 35 and 36 into Eqs 33 and 34 respectively, and it is easy to prove that $\frac{\partial^{2} L_{k}^{(4)}}{\partial^{2} y}<0, \frac{\partial^{2} L_{j}^{(4)}}{\partial^{2} x}<0$.So $L_{k}(y)^{(4)}, L_{j}(x)^{(4)}$ is a convex function, $\frac{\partial L_{k}^{(4)}}{\partial y}=0, \frac{\partial L_{j}^{(4)}}{\partial x}=0$, we can get Eqs 37 and 38 .

$$
\begin{aligned}
& x_{o p t}^{(4)}=\frac{2 B_{k} E_{j} T_{1}\left(E_{j} T_{1} b+E_{k} T_{1} b \alpha+J_{c} b-a \alpha+b \alpha s\right)}{-8 B_{j} B_{k} \alpha^{2}+B_{j} E_{k}^{2} T_{1}^{2} b \alpha^{2}+2 B_{k} E_{j}^{2} T_{1}^{2} b} \\
& y_{\text {opt }}^{(4)}=\frac{\alpha B_{j} E_{k} T_{1}\left(E_{j} T_{1} b+E_{k} T_{1} b \alpha+J_{c} b-a \alpha+b \alpha s\right)}{-8 B_{j} B_{k} \alpha^{2}+B_{j} E_{k}^{2} T_{1}^{2} b \alpha^{2}+2 B_{k} E_{j}^{2} T_{1}^{2} b}
\end{aligned}
$$

Situation 2:

$$
\begin{gathered}
L_{k}^{(5)}=T_{1}\left[C_{k}-(1-y) \alpha q E_{k}-\left((1-x) q E_{j}-C_{j}\right)\right] \\
+T_{2}\left[(1-x) q E_{j}-C_{j}\right]+\alpha q P_{k}-m q-s \alpha q-\frac{1}{2} \beta_{k} y^{2} \\
\text { s.t. } C_{k}-(1-y) \alpha q E_{k}-\left((1-x) q E_{j}-C_{j}\right) j>0 \\
L_{j}^{(5)}=-T_{2}\left[(1-x) q E_{j}-C_{j}\right]+q m-J_{c} q-\frac{1}{2} \beta_{j} x^{2} \\
\text { s.t. }\left\{\begin{array}{l}
(1-x) q E_{j}-C_{j}>0 \\
C_{k}+C_{j}>(1-y) \alpha q E_{k}+(1-x) q E_{j}
\end{array}\right.
\end{gathered}
$$

Proposition 5 : When real estate developers have surplus carbon quotas and building materials companies' carbon quotas are insufficient, internal carbon trading can meet the needs of building materials companies, and real estate developers will sell the remaining carbon quotas on the external market. In this case, there are $q_{o p t}, m_{o p t}, x_{o p t}$, and $y_{o p t}$, which maximize the profits of real estate developers and building materials companies.

Proof. Constructing Lagrange multipliers for Eqs 39 and $\mathbf{4 0}$ and solving, we can get Eqs 41 and $\mathbf{4 2}$.

$$
\begin{gathered}
m_{\text {opt }}^{(5)}=\frac{a \alpha+b\left(E_{j} T_{1} x-E_{j} T_{1}-2 E_{j} T 2 x+2 E_{j} T 2+E_{k} T_{1} y \alpha-\alpha E_{k} T_{1}+J_{c}-\alpha s\right)}{2 b} \\
q_{o p t}^{(5)}=\frac{b\left(E_{j} T_{1} x-E_{j} T_{1}-J_{c}\right)+\alpha\left(E_{k} T_{1} b y-E_{k} T_{1} b+a-b s\right)}{4 \alpha^{2}}
\end{gathered}
$$


Bring Eqs 41 and 42 into Eqs 39 and 40 respectively, and it is easy to prove that $\frac{\partial^{2} L_{k}^{(5)}}{\partial^{2} y}<0, \frac{\partial^{2} L_{j}^{(5)}}{\partial^{2} x}<0$.So $L_{k}(y)^{(5)}, L_{j}(x)^{(5)}$ is a convex function, $\frac{\partial L_{k}^{(5)}}{\partial y}=0, \frac{\partial L_{j}^{(5)}}{\partial x}=0$, we can get Eqs 43 and 44 .

$$
\begin{aligned}
& x_{o p t}^{(5)}=\frac{2 B_{k} E_{j} T_{1}\left(E_{j} T_{1} b+E_{k} T_{1} b \alpha+J_{c} b-a \alpha+b \alpha s\right)}{-8 B_{j} B_{k} \alpha^{2}+B_{j} E_{k}^{2} T_{1}^{2} b \alpha^{2}+2 B_{k} E_{j}^{2} T_{1}^{2} b} \\
& y_{o p t}^{(5)}=\frac{\alpha B_{j} E_{k} T_{1}\left(E_{j} T_{1} b+E_{k} T_{1} b \alpha+J_{c} b-a \alpha+b \alpha s\right)}{-8 B_{j} B_{k} \alpha^{2}+B_{j} E_{k}^{2} T_{1}^{2} b \alpha^{2}+2 B_{k} E_{j}^{2} T_{1}^{2} b}
\end{aligned}
$$

Based on the above conclusions, it is easy to prove the following conclusions:

1) $\frac{\partial x_{o p t}^{(i)}}{\partial y_{o p t}^{(i)}}=\frac{2 B_{k} E_{j}}{\alpha B j E_{k}}>0(i=1,2,3,4,5), \frac{\partial y_{o p t}^{(i)}}{\partial x_{o p t}^{(i)}}=\frac{\alpha B j E_{k}}{2 B_{k} E_{j}}>0(i=1,2,3,4,5)$

2) 当 $E_{j}=E_{k}, B_{j}=B_{j}$ 时, $\frac{\beta_{j} x o p t^{2}}{\beta_{k} y o p t^{2}}=\frac{4}{\alpha^{2}}$

3) $\frac{\partial q_{o p t}{ }^{(i)}}{\partial x}=\frac{\alpha E_{j} T_{1}}{4 \alpha^{2}}(i=1,2,3,4,5), \frac{\partial q_{o p t} t^{(i)}}{\partial y}=\frac{b E_{k} T_{1}}{4 \alpha}(i=+1,2,3,4,5)$

4) $m_{o p t}{ }^{(1)}-m_{o p t}{ }^{(3)}>0, \quad m_{o p t}{ }^{(2)}-m_{o p t}{ }^{(3)}>0$, $m_{o p t}{ }^{(1)}-m_{o p t}{ }^{(5)}>0, m_{o p t}{ }^{(4)}-m_{o p t}{ }^{(5)}>0$

5) $x_{o p t}{ }^{(1)}=x_{o p t}{ }^{(2)}=x_{o p t}{ }^{(3)}=x_{o p t}{ }^{(4)}=x_{o p t}{ }^{(5)}$,

$y_{o p t}{ }^{(1)}=y_{o p t}{ }^{(2)}=y_{o p t}{ }^{(3)}=y_{o p t}{ }^{(4)}=y_{o p t}{ }^{(5)}$

The following conclusions can be drawn:

1) The low-carbon degree of building materials is directly proportional to the low-carbon degree of residential buildings, and vice versa; whether it is internal carbon trading or external carbon trading, the emission reduction of one side of building materials business and real estate business can promote the active emission reduction of the other side.

2) When $E_{j}=E_{k}, B_{j}=B_{j}$, the ratio of the abatement cost of building materials business and real estate business is $\frac{4}{\alpha^{2}}$.

3) The order quantity of building materials is directly proportional to the low-carbon degree of building materials and residential buildings and has nothing to do with the form of carbon trading.

4) The optimal selling price of building materials is related to the form of carbon trading. Internal carbon trading and free carbon allowances provided by real estate developers can reduce the selling price of building materials.

5) The optimal low-carbon degree of building materials and real estate developers depends on the price of external carbon trading and is not affected by the form of carbon trading.

\section{SIMULATION}

The real estate developer of the Yucheng residential project is Country Garden Co., Ltd, which is the largest developer of new urbanization housing in China. In recent years, Country Garden has made many investments in developing low-carbon housing and has achieved satisfactory results. Country Garden's building materials manufacturers have also invested heavily in producing low-carbon building materials and strive to reduce carbon emissions. This project can reflect the efforts made by Chinese

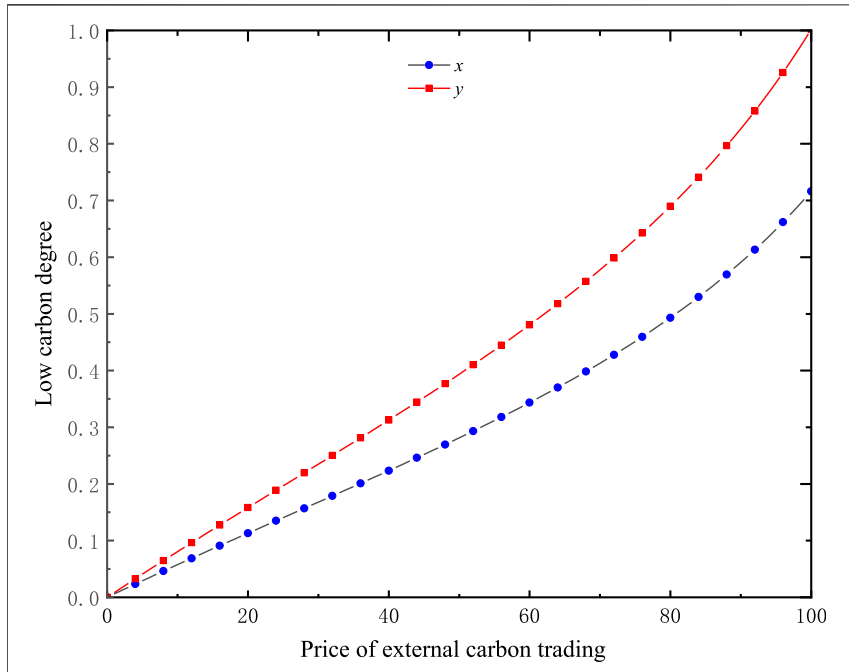

FIGURE 1 | The impact of external carbon trading prices on the degree of low carbon.

real estate developers and building materials companies to develop low-carbon housing.

The cost of $\mathrm{C} 30$ concrete used in the Yucheng residential project in Shandong Province, China, is $J_{c}=0.35$ thousand RMB/ $\mathrm{m}^{3}, \alpha=3$ (Gao, 2020); The carbon emission of concrete is $0.193 \mathrm{t} /$ $\mathrm{m}^{3}$, and the carbon emission during the construction process is $0.225 \mathrm{t} / \mathrm{m}^{3}(\mathrm{Wu}, 2017)$. The models are compared and analyzed through MATLAB, in order to obtain valid conclusions and provide decision support for the government, real estate developers and building materials companies.

\subsection{The Impact of External Carbon Trading Prices on Low Carbon Degree}

As shown in Figure 1, when only external carbon trading is conducted, the low-carbon degree of real estate developers and building materials dealers increases with the increase of external carbon trading prices, and the low-carbon degree of real estate developers is significantly higher than that of building materials.

\subsection{The Impact of Carbon Trading on the Order Volume of Building Materials}

According to the above conclusion, it is easy to prove that $q_{o p t}{ }^{(1)}=q_{o p t}{ }^{(2)}=q_{o p t}{ }^{(3)}=q_{o p t}{ }^{(4)}=q_{o p t}{ }^{(5)}$. Therefore, the optimal selling price of building materials has nothing to do with which carbon trading method is adopted but is related to the low carbon degree of building materials and the low carbon degree of residential buildings. It can be seen from Figure 2 that the optimal selling price of building materials is directly proportional to the low carbon degree of building materials and the low carbon degree of residential buildings.

When the low carbon degree of building materials and residential buildings are both 0.5 , the change in the purchase 


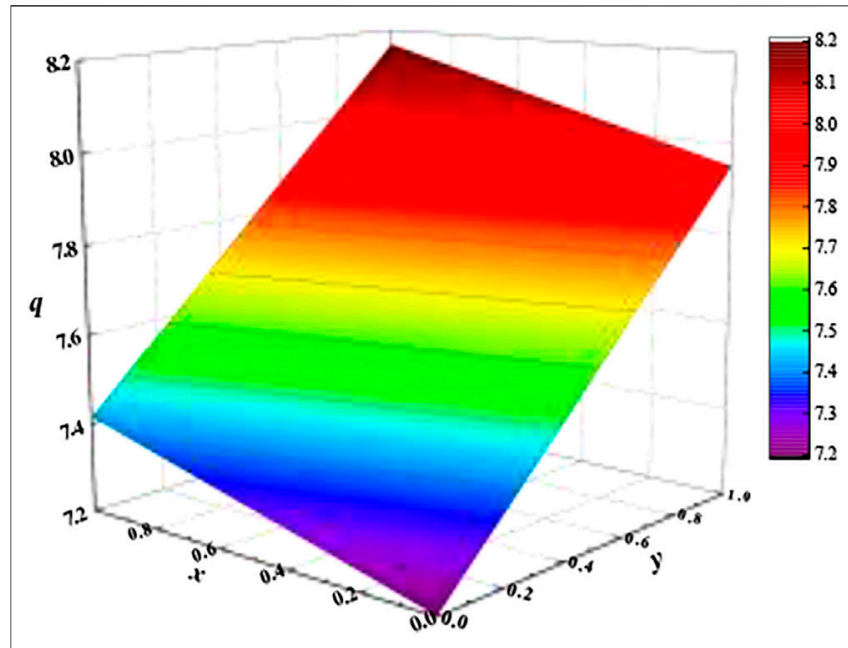

FIGURE 2 | Building materials price and low carbon degree.

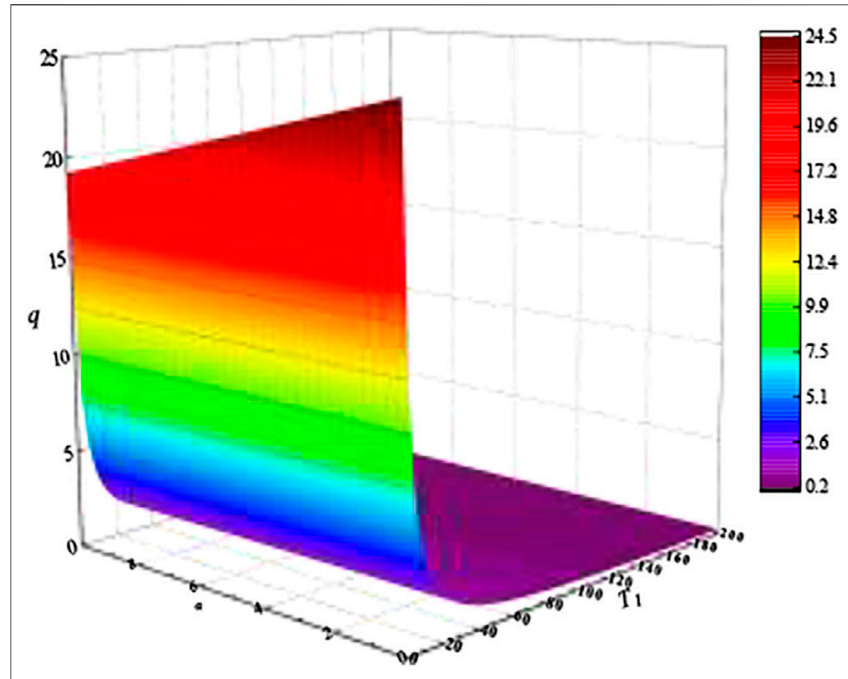

FIGURE 3 | Building materials prices, building materials usage coefficients and external carbon trading prices.

volume of building materials is shown in Figure 3. It can be seen from Figure 3 that the order quantity of building materials decreases with the increase of $\alpha$ and decreases with the rise of the external carbon trading price. When $T_{1}>60$, the order quantity of building materials decreases sharply, indicating that excessively high exterior carbon trading prices will put massive pressure on building materials companies, which is not conducive to the development of enterprises.

\subsection{The Impact of Carbon Allowances and Carbon Trading Prices on Corporate Profits}

1. Carbon allowances and corporate profits under the external transaction model

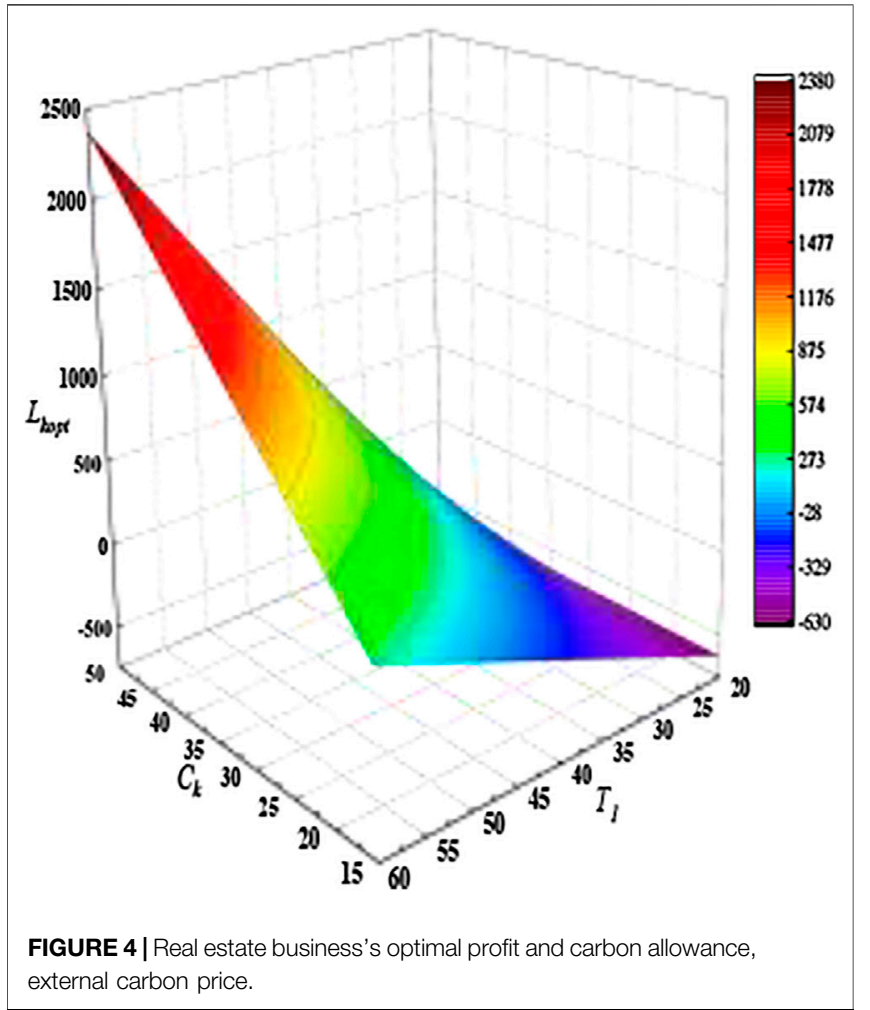

According to Eq. 12 and 15, Eq. 16, the optimal low-carbon degree of real estate developers is $0.0061\left(y_{o p t}=0.0061\right)$, the optimal low-carbon degree of building materials dealers is $0.0055\left(x_{o p t}=\right.$ $0.0055)$, and the optimal order quantity of building materials is $7.207\left(q_{o p t}=7.207\right)$. Bringing $y_{o p t}, x_{o p t}$, and $q_{o p t}$ into Eqs 1 and 2, the relationship between the maximum profit of building materials dealers and real estate developers, carbon allowances, and carbon trading prices can be obtained, as shown in Figures 4, 5 .

From Figure 4, when $(1-x) q E_{j}>C_{j}$ is satisfied, the optimal profit of the real estate agent is positively correlated with the carbon allowance and the external carbon transaction price. It can be seen from Figure 5 that when $(1-x) q E_{j}>C_{j}$ is satisfied, the optimal profit of the building materials business increases with the increase of the carbon allowance and decreases with the rise of the external carbon trading price.

Internal carbon trading will only occur when the real estate business's carbon allowance is surplus, and the building material business's carbon allowance is insufficient. When the carbon allowances of building materials companies and real estate developers meet $C_{k}-(1-y) \alpha q E_{k}>0,(1-x) q E_{j}-C_{j}>0$ and $C_{k}+C_{j}>(1-y) \alpha q E_{k}+(1-x) q E_{j}$, let $C_{k}=5$ and $C_{j}=1.2$. The relationship between corporate profits and carbon allowances and carbon trading prices can be obtained during internal carbon trading, as shown in Figures 6, 7. It can be seen that the optimal profit of real estate developers increases with the increase of carbon allowances, and the optimal profit of building materials companies does not change significantly with the increase of carbon allowances. The profits of real estate developers slightly decrease with the rise of internal carbon trading prices. In contrast, the earnings of building materials companies increase 


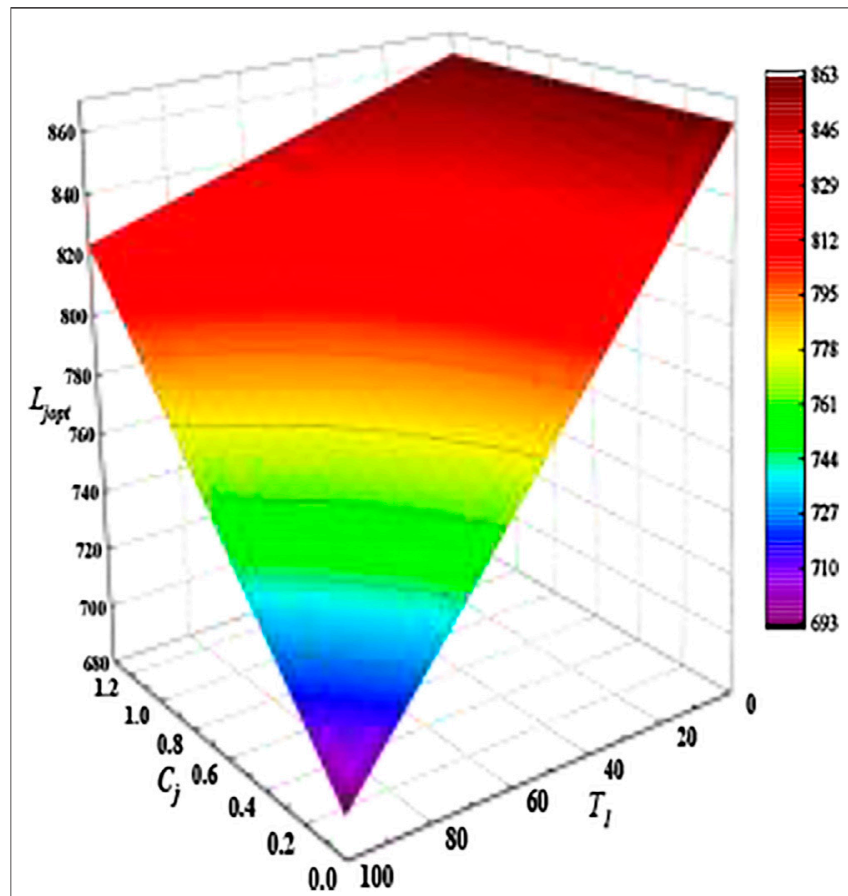

FIGURE 5 | Optimal profit and carbon allowance of building materials business, external carbon price.

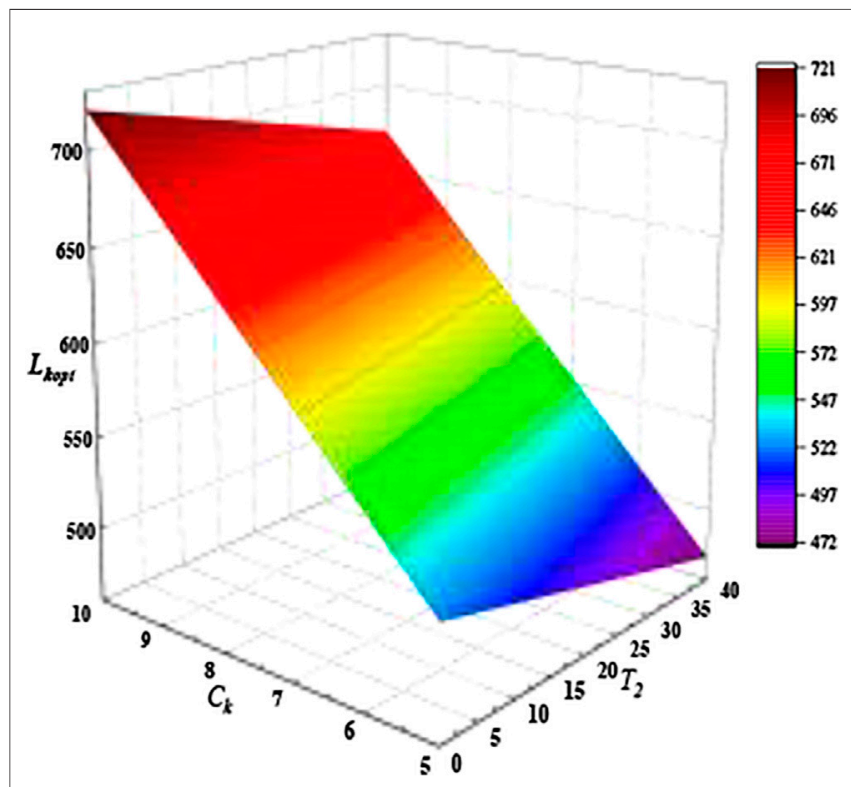

FIGURE 6 | Real estate business's optimal profit and carbon allowance, internal carbon price.

with the increase of internal carbon trading prices. This is because the optimal selling price of building materials $m_{o p t}$ is affected by the internal trading price $T_{2}$. With the rise of $T_{2}, m_{\text {opt }}$ increases, which leads to an increase in the profits of building materials companies and a decrease in the profits of real estate companies.

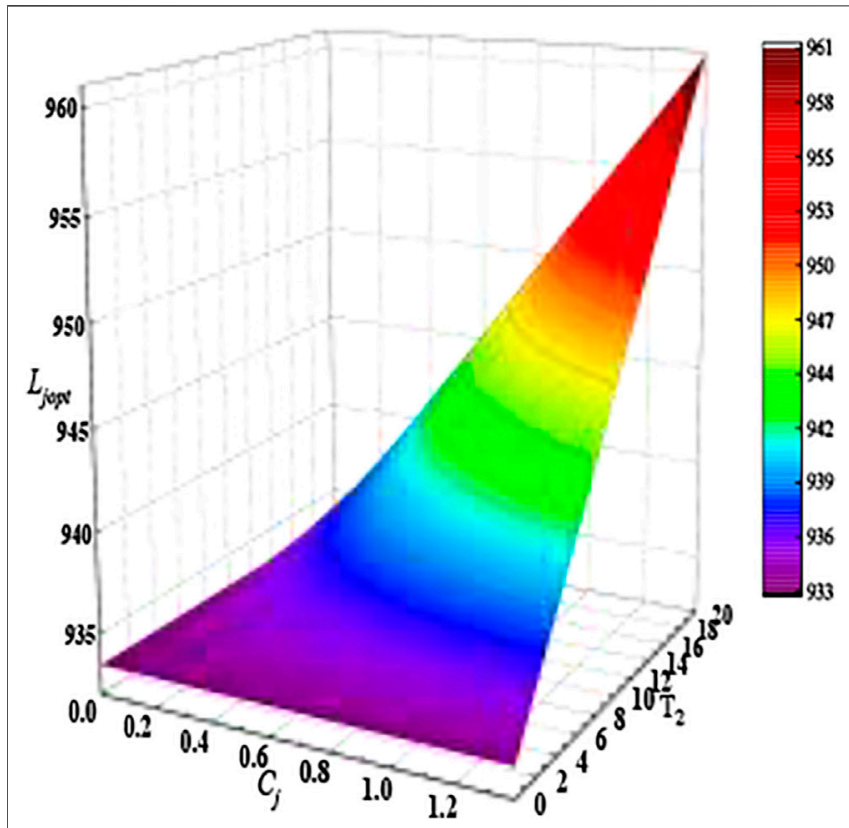

FIGURE 7 | Building materials business's optimal profit and carbon allowance, internal carbon price.

\subsection{Discussion}

In external carbon trading, the low carbon level of real estate developers is significantly higher than that of building materials manufacturers. This is because real estate developers are in a leading position in the market. The strategies of building materials manufacturers change with the real estate developers' plans. Therefore, the government should actively guide real estate developers to reduce carbon emissions when formulating policies.

When the external carbon price is reasonable, the higher the low carbon level of building materials, the higher the sales volume. However, when the external carbon trading price is too high, the profits of enterprises will plummet, which is not conducive to the development of enterprises. Therefore, in the early stage of carbon trading, carbon trading prices should be reasonably set, and enterprises should be actively guided to carry out low-carbon innovation.

Internal carbon trading can increase the profits of building materials manufacturers and increase the enthusiasm of building materials manufacturers to reduce carbon emissions. Therefore, when formulating carbon trading policies, the government should appropriately relax carbon trading restrictions on manufacturers, encourage internal carbon trading, and promote coordinated emission reductions by building materials manufacturers and real estate developers.

\section{CONCLUSION AND FUTURE WORK}

In this paper, under the three carbon trading models, five carbon trading models for real estate developers and building materials dealers are established, and the following conclusions are obtained: 
1) Regardless of internal carbon trading and external carbon trading, both real estate developers and building materials dealers have the optimal order quantity (qopt), the optimal selling price of building materials (mopt), the optimal low carbon degree of building materials (xopt), and the optimal low carbon degree of residential houses (yopt).

2) The low-carbon degree of building materials is directly proportional to the low-carbon degree of residential buildings, and vice versa; whether it is internal carbon trading or external carbon trading, the emission reduction of one side of the building materials business and the real estate business can promote the emission reduction of the other; The optimal low-carbon degree of real estate developers depends on the external carbon transaction price. The higher the external carbon transaction price, the higher the optimal low-carbon degree of building materials and real estate developers, and the carbon trading model is not affected.

3) The optimal order quantity of building materials has nothing to do with the adopted carbon trading method. The order quantity of building materials is directly proportional to the low carbon degree of building materials and residential buildings. The order quantity of building materials decreases with the increase of $a$ and falls with the external carbon trading price increase.

4) Internal carbon trading can increase the profits of building materials manufacturers and reduce the selling prices of building materials, thereby increasing their enthusiasm for carbon emission reduction.

5) When only external carbon trading is conducted, the optimal profit of real estate developers is positively correlated with carbon allowances and exterior carbon trading prices, and the optimal profit of building materials dealers is positively correlated with carbon allowances and negatively correlated with external carbon trading prices.

\section{REFERENCES}

Bai, Q., Chen, M., and Xu, L. (2017). Revenue and Promotional Cost-Sharing Contract versus Two-Part Tariff Contract in Coordinating Sustainable Supply Chain Systems with Deteriorating Items. Int. J. Prod. Econ. 187, 85-101. doi:10. 1016/j.ijpe.2017.02.012

Benjaafar, S., Li, Y., and Daskin, M. (2013). Carbon Footprint and the Management of Supply Chains: Insights from Simple Models. IEEE Trans. Automat. Sci. Eng. 10 (1), 99-116. doi:10.1109/TASE.2012.2203304

Chang, Y., Ries, R. J., and Wang, Y. (2010). The Embodied Energy and Environmental Emissions of Construction Projects in China: An Economic Input-Output LCA Model. Energy Policy 38, 6597-6603. doi:10.1016/j.enpol.2010.06.030

Chen, W., and Hu, Z.-H. (2018). Using Evolutionary Game Theory to Study Governments and Manufacturers' Behavioral Strategies under Various Carbon Taxes and Subsidies. J. Clean. Prod. 201, 123-141. doi:10.1016/j.jclepro.2018. 08.007

Ding, Z. G., Chen, H., and Xu, Q. (2020). Research on the Timing Decision of LowCarbon Technology Adoption in Supply Chain under the Double Risks of Carbon Trading and Carbon Tax. Soft Sci. 34 (07), 101-107. doi:10.13956/j.ss. 1001-8409.2020.07.17

Gao, H. H. (2020). Research on the Influencing Factors and Control of the Cost of Prefabricated concrete Buildings. Beijing: Beijing Jiaotong University. doi:10. 26944/d.cnki.gbfju.2020.000875
6) In the case of the coexistence of internal carbon trading and external carbon trading, the optimal profit of real estate developers increases with the rise of carbon allowances, and the optimal profit of building materials companies does not change significantly with the increase of carbon allowances. The earnings of real estate developers slightly decrease with the increase of internal carbon trading prices. In contrast, the profits of building materials dealers increase with internal carbon trading prices.

The conclusions of this paper can provide a valuable reference for the formulation of carbon trading policies and the development strategies of building materials manufacturers and real estate developers. Carbon tax policy is also an important tool to promote corporate carbon emission reduction. This paper does not discuss the optimal strategies of building materials manufacturers and real estate developers in the context of the carbon tax. Therefore, further research can aim to answer how the carbon tax policy promotes the development of low-carbon housing.

\section{DATA AVAILABILITY STATEMENT}

The original contributions presented in the study are included in the article/supplementary material, further inquiries can be directed to the corresponding author.

\section{AUTHOR CONTRIBUTIONS}

QY: Conceptualization (lead); writing-original draft (lead); formal analysis (lead); writing-review and editin g (equal); software (lead). LS: Conceptualization (supporting); review and editing (equal).

Lin, B., and Liu, H. (2015). CO2 Mitigation Potential in China's Building Construction Industry: A Comparison of Energy Performance. Building Environ. 94, 239-251. doi:10.1016/j.buildenv.2015.08.013

Luo, Z., Cang, Y., Zhang, N., Yang, L., and Liu, J. (2019). A Quantitative ProcessBased Inventory Study on Material Embodied Carbon Emissions of Residential, Office, and Commercial Buildings in China. J. Therm. Sci. 28 (6), 1236-1251. doi:10.1007/s11630-019-1165-x

Ma, M., and Cai, W. (2018). What Drives the Carbon Mitigation in Chinese Commercial Building Sector? Evidence from Decomposing an Extended Kaya Identity. Sci. Total Environ. 634, 884-899. doi:10.1016/j.scitotenv.2018. 04.043

Ma, Xueli., Zhao, Ying., Bai, Qingguo., and Bo, Hongguang. (2021). Optimal Decision and Coordination of Three-Level Cold Chain of Fresh Products Considering Preservation Efforts and Carbon Emission Reduction Efforts. China Manag. Sci., 1-15. Available at: http://kns.cnki.net/kcms/detail/11. 2835.g3.20210926.1435.004.html.

National Bureau of Statistics of China (2020). China Statistical Yearbook [M]. Beijing: China Statistics Press.

Qu, J. S., Wang, L., and Qiu, J. L. (2014). Regional Analysis of Fixed Carbon Emissions from Residential Buildings in China. J. Lanzhou Univ. (Natural Sci. Edition) 50, 200-207. doi:10.3969/j.issn.0455-2059.2014.02.009

Shen, L. F., and Li, Q. M. (2011). Research on the Connotation of "low Carbon Housing" and the Path of Construction and Development. Mod. Manag. Sci. 10, 31-33. CNKI:SUN:XDGL.0.2011-10-010. 
Shen, L., Song, X., Wu, Y., Liao, S., and Zhang, X. (2016). Interpretive Structural Modeling Based Factor Analysis on the Implementation of Emission Trading System in the Chinese Building Sector. J. Clean. Prod. 127, 214-227. doi:10. 1016/j.jclepro.2016.03.151

Song, X., Lu, Y., Shen, L., and Shi, X. (2018). Will China's Building Sector Participate in Emission Trading System? Insights from Modelling an Owner's Optimal Carbon Reduction Strategies. Energy policy 118, 232-244. doi:10.1016/j.enpol.2018.03.075

Wang, F., Liu, J., and Cai, L. (2016). Supply Chain Coordination under Carbon Trading Mechanism in Case of Conflict. J. Railway Sciebce\&Engineering 5, 1000-1006. doi:10.19713/j.cnki.43-1423/u.2016.05.030

Wang, W. L., and Cheng, T. Y. (2021). The Evolutionary Game Analysis of Supply Chain Operation Decision-Making in the Context of Carbon Trading. Syst. Eng. Theor. Pract. 41 (05), 1272-1281. Available at: https://kns.cnki.net/kcms/detail/detail. aspx?FileName=XTLL202105016\&DbName $=$ DKFX2021.

Wang, Y., and Hou, G. (2020). A Duopoly Game with Heterogeneous green Supply Chains in Optimal price and Market Stability with Consumer green Preference. J. Clean. Prod. 255, 120161-161. doi:10.1016/j.jclepro.2020.120161

Wei-Jun, M. (2010). Comparation of Subsidy and Cooperation Policy Based on Emission Reduction R\&D. Syst. Eng. 28 (11), 123-126. CNKI:SUN: GCXT.0.2010-11-021.

Wu, S. Y. (2017). Research on Carbon Emissions of Construction Projects Based on Bill of Quantities. Fuzhou: Fujian Agriculture and Forestry University. Available at: https:// kns.cnki.net/KCMS/detail/detail.aspx?dbname=CMFD201801\& filename $=1017072648 . \mathrm{nh}$.

Xiao, J. Z., Li, Y., and Ding, T. (2016). Evaluation of CO2 Emissions during the Life Cycle of Recycled concrete. J. Southeast Univ. (Natural Sci. Edition) 46, 1088-1092. doi:10.3969/j.issn.1001-0505.2016.05.032

Xu, J. J., Wu, C. H., Wang, H., and Chen, J. (2020). Evaluation of Carbon Emissions of Recycled Concrete Green Buildings and Sensitivity Analysis of Grey Parameters. J. Xi'an Univ. Architecture Tech. 52 (03), 396-403. doi:10. 15986/j.1006-7930.2020.03.013
Xu, J., Chen, Y., and Bai, Q. (2016). A Two-Echelon Sustainable Supply Chain Coordination under Cap-And-Trade Regulation. J. Clean. Prod. 135, 42-56. doi:10.1016/j.jclepro.2016.06.047

Yang, Z. F. (2021). Research on Emission Reduction Decision-Making and Coordination of Closed-Loop Supply Chain under Carbon Trading Policy. Dalian: Dalian University of Technology. doi:10.26991/d.cnki.gdllu.2021.000167

Zhang, L. R., Wang, J., and Peng, B. (2020). Study on Supply Chain Emission Reduction Decisions under the Path of Internal and External Carbon Allowance Trading. China Manag. Sci. 28 (11), 145-154. doi:10.16381/j.cnki.issn1003207x.2019.1579

Zhu, J., Fan, Y., Deng, X., and Xue, L. (2019). Low-carbon Innovation Induced by Emissions Trading in China. Nat. Commun. 10 (1), 1-8. doi:10.1038/s41467-01912213-6

Zhu, W., Feng, W., Li, X., and Zhang, Z. (2020). Analysis of the Embodied Carbon Dioxide in the Building Sector: A Case of China. J. Clean. Prod. 269, 122438. doi:10.1016/j.jclepro.2020.122438

Conflict of Interest: The authors declare that the research was conducted in the absence of any commercial or financial relationships that could be construed as a potential conflict of interest.

Publisher's Note: All claims expressed in this article are solely those of the authors and do not necessarily represent those of their affiliated organizations, or those of the publisher, the editors and the reviewers. Any product that may be evaluated in this article, or claim that may be made by its manufacturer, is not guaranteed or endorsed by the publisher.

Copyright (C) 2022 Yao and Shao. This is an open-access article distributed under the terms of the Creative Commons Attribution License (CC BY). The use, distribution or reproduction in other forums is permitted, provided the original author(s) and the copyright owner(s) are credited and that the original publication in this journal is cited, in accordance with accepted academic practice. No use, distribution or reproduction is permitted which does not comply with these terms. 